\title{
Minute Times Picomole Per Liter Per Kilogram
}

National Cancer Institute

\section{Source}

National Cancer Institute. Minute Times Picomole Per Liter Per Kilogram. NCI Thesaurus.

Code C112355.

Minutes times picomoles per liter, divided by kilograms. 